\title{
Establishing Inclusion in a New School: The Role of Principal Leadership
}

\author{
James Ryan \\ The Ontario Institute for Studies in Education
}

\begin{abstract}
This article describes a study that documents the attempts of administrators of a new school to introduce and sustain inclusive leadership and program arrangements over the course of the first 3 years of the school's life. The data illustrate that while they were able to succeed on a number of levels, they also encountered a number of challenges. Principal among these were the departure of the first principal after the second year, a rapid increase in the school population, as well as the challenges that accompany most schools when they attempt to implement inclusive practices.
\end{abstract}

Over the past few years educational interest in inclusion has increased. Many schools are now looking to include teachers, students, and parents in many aspects of their operations (Ryan, 2006a). Governments are also promoting inclusion. The Ontario Ministry of Education (2009), for example, in their Realizing the Promise of Diversity: Ontario's Equity and Inclusive Education Strategy report, encouraged school boards and schools in their respective jurisdictions to "strive to ensure that all members of the school community will feel safe, comfortable and accepted" (p. 10), wanting "all staff and students to value diversity and to demonstrate respect for others and a commitment to a just, caring society" (p. 10). The versions of inclusion in these and other testimonies target a vision of inclusion that is more comprehensive than the longstanding one that revolves exclusively around students with exceptionalities (see, for example, Ainscow, 2005; Booth, 1996; Lupart, 1998; Slee, 2001). While acknowledging those who continue to advocate for the inclusion of students with exceptionalities, proponents of these newer versions of inclusion also point out the threat to inclusion from exclusive practices associated with racism, classism, sexism, and homophobia, among others (Dei, James, Karumancherry, James-Wilson, \& Zine, 2000; Riley \& Rustique-Forrester, 2002; Ryan, 2006a). Similar to some of those who have traditionally advocated for students with exceptionalities (e.g., Ainscow, 2005), they see inclusion as a process that (a) targets exclusive systemic practices; (b) emphasizes the importance of access, participation, and achievement of all students; and (c) advocates for the meaningful par- 
ticipation of all members of school communities in the decision-making activities of schools and school systems.

Despite the best intentions, it is not always easy to establish inclusive practices in schools. Advocates of inclusion regularly face obstacles when they attempt to do so. Among other impediments, they must contend with the hierarchical systems in which they work; resistance from fellow educators, parents, and students; traditional exclusive conventions; quasimarket environments; and unmanageable workloads (Ryan, 2003, 2006a, 2007; Ryan \& Rottmann, 2009; Theoharis, 2007). It is particularly challenging for champions of inclusion to introduce inclusive practices into organizations that have longstanding traditions and cultures. Although not prohibitive, change agents will experience difficulties trying to move members away from entrenched conventions to embrace new and unfamiliar practices (Fullan, 2001). Those who attempt to introduce inclusion simply have an additional challenge. It would seem, then, that it would be easier to introduce inclusion into a setting that either does not have an already entrenched culture or is receptive to inclusion. Both of these conditions can exist in new schools, particularly in settings where the principal has the freedom to choose the staff and promote his or her own inclusive philosophy. The article represents an effort to investigate this sort of scenario. It describes a study that looks at a new school where the first principal attempted to put into practice his inclusive philosophy.

Little research exists on new schools. The research that has been conducted tends to target particular institutions, like Montessori schools (North American Montessori Teachers Association, 2009) or small schools (Ancess, 1997); provides advice or formulae (Ancess, 1997; Lake, Winger, \& Petty, 2002); or outlines problems associated with starting new schools (Jennings, 1992). No research explores how inclusion is established in new schools. This article intends to address this gap.

\section{Inclusive Practice}

The practice of inclusion has been part of education for some time now, generally associated with the education of "special needs," "exceptional," or "differently-abled" students (Ainscow, 2005; Booth, 1996; Lupart, 1998; Slee, 2001). Inclusion has become an issue, in part, because of the way in which the needs of students with exceptionalities have been understood and supported over the years. As schooling expanded to cater to large numbers of students in the previous century, educators found that not all students were able to cope with the standardizing conventions associated with these institutions. Instead of blaming the organizations for these difficulties, however, many educators and others held students responsible. Drawing on quasimedical and psychological discourses, they came to the conclusion that the reason these students were not performing well at school was because they were "backward," "slow," or "defective" (Slee, 2001). Educators and other experts concluded that such students were plagued with physical, behavioural, or cognitive disabilities that prevented them from learning like other students. The eventual solution, then, became a technical one: These backward students had to be identified and then subjected to unique treatment. But because, by definition, students with exceptionalities struggled to learn in conventional settings, educators felt that they needed to be segregated from mainstream students. For many students, however, this segregation did not lead to success. Slee (2001) and others contended that these arrangements had neither equipped students to exercise their rights as citizens nor to accept their responsibilities. This is one reason that 
many advocate that school systems abandon this segregation and include exceptional students within general classrooms with average-achieving students.

Other scholars who are concerned with the education of students with exceptionalities have also recognized that students with physical, cognitive, and behaviour issues are not the only ones who are excluded from traditionally organized school systems. This has become particularly apparent for those who look at the issue from an international perspective (Ainscow, 2005; UNESCO, 2003). Ainscow (2005), for example, maintained that on an international scale, students can become excluded by virtue of their assignment to categories other than exceptionality or no exceptionality. He noted that social exclusion is a consequence of attitudes and responses to diversity in race, social class, ethnicity, religion, and gender, in addition to ability. As a result, Ainscow believed that inclusive schools need to welcome diversity among all learners, not just those with exceptionalities. This perspective, which Lupart (1998) called the "minority group" concept, also coincides with the view of other inclusive-minded scholars in education who acknowledge the importance of attending to issues of race, class, gender, sexual orientation, and ability (Dei et al., 2000; Riley \& Rustique-Forrester, 2002; Ryan, 2006a), as well as those researchers who study poverty in Europe.

Researchers studying poverty in Europe have also used the terms inclusion and exclusion (Byrne, 1999; Madanipour, Cars, \& Allen, 1998; Munck, 2005). They prefer to see social injustice not just in terms of poverty, but also as a multi-dimensional process in which various forms of exclusion are combined. Among other things, they are interested in the extent to which men, women, and children have access to current social, economic, political, or cultural systems - to participation in decision-making and political processes, to employment and material resources, and to integration in common cultural processes like education (Madanipour et al., 1998; Walker \& Walker, 1997). Within this perspective, individuals and groups are excluded when they lack the resources to obtain certain types of diets, to participate in various activities, and to enjoy the living conditions and amenities that are customary. The advantage of this approach is that it avoids blaming individuals, emphasizing instead the relational and structural nature of their misfortunes. Advocates contend that structural processes, rather than individuals and groups, systemically create barriers and inequalities that prevent the social advancement of the poor, disempowered, and oppressed. Seeing the misfortunes of individuals and groups in terms of inclusion/exclusion provides a useful framework for action. Perhaps the most attractive feature of viewing not just poverty but other forms of injustice in terms of inclusion, though, is its positive focus. While it does highlight the negative and unjust side of life, it also provides us with a sensible and practical alternative: inclusion. The goal of inclusion is to see that everyone is included in the social processes common to communities and schools (Ryan, 2006b).

In recent times, schools and governments have taken up this project. Like the Ontario Ministry of Education (2009), they have endeavored to ensure that students, parents, and educators are meaningfully included in the most important educational processes within schools. Key in these inclusive projects is leadership. Inclusive efforts, no matter how well intentioned, will not succeed or sustain themselves if they are not entrenched in the accompanying leadership arrangements (Ryan, 2003, 2006a). This means that students, parents, and teachers will need to have a meaningful voice in decision- and policy-making processes. The person best placed to influence these leadership configurations at the school level is the principal. If leadership is to be inclusive then the principal must be supportive (Ryan, 2003). But inclusion involves much more than leadership arrangements. If schools are truly serious about promoting inclusion then they also need to attend to programming. And so principals must also ensure that the curriculum, 
pedagogy, and various school initiatives are inclusive. The intent here is to make sure that these aspects of formal schooling make it possible for students - and their parents - to identify with their surroundings and to be exposed to curricular offerings and pedagogy that allow them access to the knowledge that the school has to offer (Dei et al., 2000).

Research indicates that administrators who promote inclusive programs and leadership arrangements tend to reflect on leadership arrangements, attempt to include as many individuals in school activities and processes as possible, and advocate for inclusion (Ryan, 2003, 2006a). The more reflective leaders realize that inclusion works best if leadership is seen as a collective process rather than a hierarchical practice that revolves around one person. Individualist and hierarchical practices, by default, exclude many. They also make it difficult to provide students, teachers, and parents with ways to become involved in various school activities, including instruction, curriculum, budget, and hiring. To overcome these and other barriers to inclusion, administrators will need to advocate for inclusion and for marginalized groups. This requires that they foster a process that allows them to create and communicate an inclusive future and to persuade others to commit to that future (Thousand \& Villa, 1994). This can occur if administrators forge relationships with like-minded others, including marginalized groups (Oakes \& Lipton, 2002); share with others the theoretical, ethical, and research-based rationales for inclusion; create a certain amount of discomfort around exclusive practices (Thousand \& Villa, 1994); and if necessary, make inclusion nonnegotiable (Keys, Hanley-Maxwell, \& Capper, 1999).

Inclusive-minded administrators also look to educate their entire school communities, promote dialogue, adopt inclusive policy-making, and incorporate whole school approaches and cultures (Ryan, 2003, 2006a). They understand that members of their school communities have much to learn about each other and about issues of inclusion and exclusion. Educating school communities requires a combination of formal and informal learning, organizational learning options, and an approach that maintains pressure to change exclusive practices without being too confrontational (Gillborn, 1995). This learning can be enhanced if administrators, students, teachers, and parents are able to look critically at the social context in which they find themselves. They can acquire this critical consciousness by pausing, stepping back from their daily routines, and inquiring into their own and others' thoughts and actions (Coombs, 2002). Administrators can also foster inclusion by making it possible for all constituents in their school communities to play a meaningful role in policy-making at the school level (Corson, 1996). All these practices are most easily achieved when inclusion is entrenched in the culture of the school.

Efforts to introduce inclusion in schools do not always meet with success. There are a number of reasons for this. Perhaps the most obvious is that educators work in culturally conservative institutions that value homogeneity, resist change, and look unfavourably on challenges (Rizvi, 1993; Ryan, 2003; Walker \& Walker, 1998). Moreover, many of the people who can do the most to introduce inclusion - most of them administrators - are themselves conservative, socialized into a system that rewards supporters (Ryan, 2003). Administrators may have difficulty working outside of the traditional bureaucratic cultures and structures to which they are accustomed, and they are not always willing to surrender power to others (Blase \& Blase, 1997; Blase \& Blase, 1999; Bolin, 1989; Kirby, 1992). But even those who are able to do so find that it is difficult to escape the authority and responsibility that accompany their position because they will inevitably have to answer to others if things go wrong (Bolin, 1989; Bredeson, 1989; Wallace, 2001). Teachers may also not be keen to abandon the comfort of having others make decisions and take responsibility (Blase \& Blase, 1999; Epp \& MacNeil, 1997). Furthermore, teachers may be reluctant to participate in governance activities and may not want to break solidarity with col- 
leagues by assuming authority that their colleagues do not have (Conley, 1991; Datnow \& Castellano, 2001; Duke, Showers, \& Imber, 1980).

For many, inclusive situations will be new, and as a consequence, teachers and administrators may not know what their respective roles are or should be (Blase \& Blase, 1997; Bredeson, 1989; Datnow \& Castellano, 2001; Epp \& MacNeil, 1997; Leithwood, Jantzi, \& Steinbach, 1999). This ambiguity generates conflict and anxiety on the part of both teachers and administrators (Blase \& Blase, 1997; Blase \& Blase, 1999; Glickman, Allen, \& Lunsford, 1994; Smylie \& Brownlea-Conyers, 1992). Still, conflict is not just the result of uncertainty around roles; it also emerges as participants move into positions where they are more open about their differences (Blase \& Blase, 1997; Glickman et al., 1994). This conflict is not necessarily always negative, however.

Attempts at implementing inclusive arrangements also face other impediments. Two of these are time and workload (Blase \& Blase, 1999; Bredeson, 1989; Conley, 1991; Duke et al., 1980; Epp \& MacNeil, 1997; Short \& Greer, 1997). Implementing inclusion requires extra work and this work requires additional time. Not surprisingly, teachers often find they simply do not have enough time to devote to these activities. Traditional school time patterns do not always help. Inflexible schedules make it difficult for those who teach to engage in other activities (Conley, 1991). Also, teachers tend to resent activities that cut into time normally spent on classroom-related activities, particularly if they do not have any apparent effect on the classroom (Leithwood et al., 1999). Implementing inclusive arrangements also becomes more difficult when teachers feel their opinions are not valued and acted upon and when they receive little support and few resources (Blase \& Dungan, 1994; Epp \& MacNeil, 1997; Kirby, 1992; Short \& Greer, 1997).

Questions remain, however, about what happens in new schools where the principal is an advocate of inclusion, particularly in situations when he or she can choose the staff. In an effort to explore this question, the study described here examines how the principal(s) of a new secondary school attempted to establish inclusion in a new school. More specifically, it looks at how the inclusive mandate evolved over the course of the first 3 years of the school's life.

\section{The Study}

This study was part of a larger project that explored inclusive leadership practices. It consisted of three parts. The first included interviews with 30 principals; the second involved a survey; and the third involved case studies. This article focuses on one of the case studies: Adam Bower School (a pseudonym). This school was chosen as a site for one of the case studies after the initial round of interviews. We selected Rob Powers (a pseudonym), the principal, and his school on the basis of what we perceived to be Rob's commitment to inclusion. The methods normally employed in case studies - observations, interviews, and documents (Merriam, 1998) were used to illuminate efforts to implement inclusion in this school. A team of three researchers visited the school once a week for six months where they informally observed interactions in the library, cafeteria, science and computer labs, gymnasium, and staff room. They also observed specific events. For example, they attended a literacy information session for parents and a professional development session for teachers. They also set up a booth on parents' night to inform parents of the research project and to recruit them for interviews. During these observation sessions, researchers took field notes on practices and language relating to inclusion and exclusion at Adam Bower. 
Researchers also conducted formal interviews with Rob (the principal), Jean (his successor), ten teachers and two other school staff, six students, and three community members. School staff members were selected on the basis of their availability and willingness to participate in the study. All of the student participants were seniors, 18 years of age or older. They were recommended by teachers and represented a range of student views. It was more difficult to recruit parents, however. Despite persistent efforts, we were only able to arrange three interviews. Interviews lasted between 30 and 60 minutes and were conducted in the school. Participants were asked about (a) their perceptions of inclusion; (b) policies, programs, and strategies designed to promote inclusion; and (c) experiences relating to inclusion and exclusion in the school. Questions included, for example, What does inclusion mean to you? How do you promote inclusion in your school? and Can you tell me about a situation where you promoted inclusion? Interviews were tape-recorded and transcribed.

Researchers also looked at documents, such as school policies, that pertained to issues associated with inclusion. Transcripts of the interviews and relevant polices were read and themes were eventually identified. This was accomplished with the help of N6 computer software that simplified the mechanics of moving passages of text around to identify and elaborate on the themes. The three major themes included the context of the school, the actions of the principals, and the programs that they promoted. The actions of the principals theme displayed a number of sub-themes, including philosophy of inclusion, students, teachers, parents, committees, resistance, and transitions. The program theme included diversity, specialized programs, pedagogy, and curriculum sub-themes.

\section{Adam Bower School}

Rob Powers initially expressed an interest in the position of principal of Adam Bower because he saw it as an opportunity to "build an inclusive environment" in what he hoped would be a "community school." Rob believed that he could shape this kind of culture from the "ground up" because this was a new school, the first built in 5 years in a school district where the population was increasing exponentially. But in the year he had to prepare for the school's opening, Rob saw his dream of a relatively small community school fade. Overcrowding in neighbouring schools forced him to abandon plans for a student body of 500 and a teaching staff of 35 , and embrace 1190 grades 9 and 10 students and 72 teachers. Eventually, as the school expanded to also host grades 11 and 12, the student and teacher population would balloon to 1700 and 135 , respectively, in a building designed for 1535 students.

Adam Bower was constructed in a suburban area that was growing quickly. The population in the general area had increased 33\% over the past 5 years (Statistics Canada, 2009). Fortyeight percent were immigrants and 57\% were "visible minorities." Of the latter, the largest group was South Asian, comprising 56\% of this population. These numbers were reflected in the school; most estimates placed the number of students of South Asian background at $80 \%$ of the entire student population. Fifty-nine percent of the students spoke a language other than English or French as their first language.

Adam Bower is situated in an area where there are many new houses. One real estate company estimated that the average house price in the area is around $\$ 300,000$. The median family income is $\$ 66,465$ (Statistics Canada, 2009). Despite the relative prosperity in the area, Rob pointed to issues not immediately visible: 


\begin{abstract}
We have a lot of inner city issues in the suburbs. And a lot of them were masked by the facades of these houses. Parents were not at home; kids were raising kids; grandparents were raising kids. And then you have the other dynamics that are operating; there's inter-generational conflict in homes; there's cultural conflict that's occurring in homes between parents and kids, more traditional versus more Western. So all those things are operating at the same time without the level of support that I think was required in the community.
\end{abstract}

Rob began his quest to ensure that these students had an inclusive educational experience a year before the school actually opened. Along the way, he was forced to deal with the unexpected population explosion. This was not the only issue that the school community had to cope with in its first 3 years. At least as traumatic was Rob's departure. He left after the second year to take up another position and was replaced by Jean who was also an advocate of inclusion, having recently played a key role in the district's equity plan. Needless to say, not everything went smoothly over the first 3 years of Adam Bower's life. Members of the school community struggled in their efforts to establish inclusive leadership and programming practices in the school.

\title{
Inaugural Leadership
}

When Rob assumed the principalship at Adam Bower, one of the first things he did was to hire faculty. In the end, he was able to hire all of his teachers save one who was a transfer. In doing so, he made sure that everyone he eventually employed shared his vision for the school. In the interviews, he asked them questions that probed their attitudes toward inclusion, collaboration, teacher learning, and commitment to students. Even though he embraced the idea of collective leadership, he nevertheless insisted that all teachers embrace his inclusive vision. He told them, "Make no mistake about it, we're going this way, [but] we're going to build that together."

In keeping with his inclusive philosophy, Rob sought input from his future constituents from the beginning. He met and surveyed all the incoming students "to get their input, to try and give them ownership of what we were going to try and be doing at the school." At the same time, he worked with the future administration - department heads and vice-principals - to find other ways to gather information not just from the students, but also from the staff and from the community about how they wanted their (inclusive) school to look.

From the outset, Rob encouraged "leadership" from students, teachers, and parents alike. It was not easy to nurture leadership among the grade 9 and 10 students when the school opened. According to Rob, in the beginning "there was not very positive or strong modeling because they were all juniors." In time, though, after the students had matured a year, the school began to "build a cadre of leaders that extended more deeply into the student body." Centred around the Music Council, Athletic Council, and Student Council, students began to make more decisions. The school staff also helped. Among other things, they attempted to identify potential student leaders in grades 8 and 9 and provide them with more opportunities. Teachers also shared in the implementation of peer coaching programs and helping out with the more formal organizations.

Teachers were also encouraged to take up leadership roles. This was a feature that one teacher (Beck) appreciated when he first came to Adam Bower. He contrasted this school with other "more traditional schools" where

a teacher like myself who is relatively young compared to the rest of the staff would feel uncomfortable starting an initiative or being part of a committee because they weren't part of that established culture or had ownership of certain aspects of school life. 
Adam Bower, however, was different. Beck noticed right away that regardless of age or background, "the principal showed a lot of confidence in every person he hired." The result was that most teachers felt comfortable taking initiatives and sitting on the various committees that made decisions about various aspects of school life. This spirit also carried over to the departmental units within the school. For the most part, most departments looked to everyone to contribute to the decisions that were made.

Aside from the various committees and administrative bodies, like the Department Head's Council, teachers were provided with the opportunity to contribute to the workings of the school through the professional learning community (PLC) setup. Rob was a strong advocate for PLCs, believing that teachers also had to be learners if students were going to have optimal learning experiences. In order to make this idea work, he provided teachers with much needed time during the school day to explore their own learning. Rob built in time during the school week - 100 minutes every Wednesday morning without students - to allow teachers to do this. In doing so, he hoped to provide opportunities for staff members to take a more active role in leadership activities, drawing on their expertise and contributing to the "democratization of a learning community" as they did so. According to Rob, it was through these and other similar activities that an inclusive culture spread broadly throughout the school.

The first 2 years were not without challenges. Aside from the difficulties of nurturing student leadership, the rapid growth of the school and the tenuous relationship with the parent community hampered efforts towards establishing inclusive leadership practices. The exponential growth made it difficult to maintain the philosophy that Rob had developed with his original 10 department heads. In the second year, when 10 of the original teachers moved on and he had to hire 35 new teachers to complement the 500 additional students, Rob noted a "drift" in the original philosophy; the new teachers did not display the same kind of orientation that their colleagues had. More than this though, the sheer size of the school made it more difficult to circulate the values to the entire school community.

The parent community was also not as involved in the school council as Rob would have liked. Initially, parents were not happy with the way that their sons and daughters were being shuffled from school to school as the school district desperately attempted to cope with the rapid population growth in the area. On the other hand, the school's strategy to bring all new students and their parents in for an interview gave the parents a chance to meet the school's administration. Even so, few parents were involved in the parent council despite efforts on the part of the school and school council members to recruit members from the community. And while enterprises, such as a Punjabi Outreach Night, managed to involve a few more parents, they continued to pay little heed to the school council. The other major complication for inclusive efforts was the departure of Rob after the second year in the life of Adam Bower.

\section{New Leadership}

Jean stepped into the principalship in the third year of the school's existence. Most teachers felt that she was a good fit as a successor to Rob. She shared his inclusive philosophy and had been involved with equity initiatives at the district level. Jean had an open door policy and sought to involve the entire school community in decision-making processes, supporting and extending the inclusive practices and structures that were initiated in the previous regime. She saw leadership as a team enterprise. She said, 
I'll be...the figurehead, but I really don't think that I can lead this building on my own. It needs that Heads Council, it needs the rest of the admin team, it needs the secretaries, the custodians... and it needs the student leaders too, to all be contributing to things.

Jean wanted "everybody to be part of a direction and leading the way." She was happy to "be part of that," but did not "want to be the only person out there."

For the most part, teachers recognized and appreciated Jean's open approach. Kathy, for example, noticed that Jean was "very open...she's always asking for opinions and feedback on different...things that they introduce." She also noted that in conjunction with the principal's attitude that there is "a lot of openness and sharing in this school" and "a lot of encouragement given to a teacher if he or she comes forward and says 'You know I want to do something."' Kathy found that Jean was always open to these kinds of overtures as long as they benefited students and the school community, and she was encouraged by this practice.

However, the road toward inclusive decision-making in the school was not entirely smooth. Some teachers noticed a change in the school in the third year. William, for example, contended that in contrast to the first 2 years, he thought that Adam Bower was increasingly "becoming like a regular school." He said,

When it first opened I guess because of the principal who was here there was a certain vision and there's a lot of attachment to that principal and to that vision. I guess with a lot of new staff and new leadership coming in...the same vision is not really shared.

It was not easy for Jean. This was her first appointment as a principal. Not only did she have to become acclimatized to a new school, she also had to learn the role of principal, not to mention finding ways to deal with a staff that had been hired by someone who shaped the general orientation of the school. Staff members recognized that it was not easy stepping into a position that was occupied by someone to whose vision and person they were attached. Rodney, for example, said,

I think that our new principal has an outstanding vision, but I just think that the rigors of being a principal for the first time, coming to a school where...there's been a lot of demands that she's had to endure.... So I think I can't fault her directly just because I don't know myself what the demands of her job necessarily entail.

Through all of this Jean championed her inclusive vision, but not without drama. One of her initiatives involved input on the schedule for the following years. One of the key issues was whether the school would retain its late start on Wednesdays. In the spirit of inclusion, she thought everyone who was to be affected by any changes in the next year's schedule-including teachers, students, and parents - should have the opportunity to voice their opinion. She encountered her first obstacle in her plan when she took it to a staff meeting. Some teachers objected to the idea of allowing students to vote. One teacher stood up and announced that students should not have a vote because the change in schedule "didn't affect their lives." When he did this, the staff applauded. Other teachers recalled the incident, also voicing their opposition. Bill did not think that the students should have a vote because he believed that it would not be "an informed vote." He did not believe that "they really understood the issues." John, on the other hand, felt that the students were simply not mature enough to be involved in such a decision.

Despite the staff opposition, Jean argued that students had their own reasons for wanting to be included in the voting. Undaunted, she went ahead with her plans to include the students. She said that she "thought that it was important enough to include the students and I just went 
ahead and did that." Her next step was to approach the student council for assistance. Members of the council arranged for students to fill out ballots on their lunch hours and then counted them. Jean also arranged to have parents vote. She had those parents who came into the office fill out ballots over the course of 2 weeks. Parents also had the opportunity to vote when they came in for parents" night. Jean said she eventually got a "significant number of parents" to cast their ballot on the issue. In the end, the school community voted to retain the late Wednesday start.

Dissatisfaction also accompanied another of the leadership initiatives championed by Rob. According to Wilbur, teachers had become increasingly "disenchanted" with the state of the professional learning community activities. He noted that in the past they looked to Rob who had "made it his personal mission" to use the PLC to fulfill the staff"s vision. He stated, "in the first two years it was thought of as something very valuable and something that we could use to inform our practice." In the third year, however, some teachers felt that they were not receiving the same level of support from administration and were beginning to question the administration's vision. Wilbur went on to say that

this year...teachers who are taking a more active leadership in the PLC are feeling a lot more stress and burden because they don't always feel supported by administration, and they also see a lot of teachers that don't necessarily buy into it the way it was the past two years.

These people felt that "it's hard to keep pushing forward." At the very least, Wilbur wished that an administrator would drop in on the PLC sessions "just to see how things are going." He said "I don't think that they have to lead the sessions, [but] to have their presence sometimes would be a bit more reassuring."

The inclusion of students in decision making also has a way to go, according to Jean, who attributed this nascent state to the fact that the school was still new and it was just the first year for Grade 12 students. Even so, she managed to solicit their views on items such as the next year's schedule, although at least one teacher did not see this as inclusion given that it was a foregone conclusion that students would vote for a schedule that allowed them to come to school 90 minutes later one day a week. Jean also supported the Student Council, Athletic Council, Student Wellness Council, student mentors, and a student leadership group, and is looking forward to a time when these groups can look "at things beyond the usual, the prom, and the dance and that kind of stuff to looking at... social action." She also saw to it that students had input on various committees and initiatives. There were mixed feelings about the impact of these student organizations, however. Some felt that students had some say in what happened. Others did not. Some students, for example, were skeptical. Jenny, a senior student, stated,

We have a Student Council, but nobody knows who they are right now. If you ask ten people, probably eight people would say "I don't know who's our leader." How can we get things done in our school or events? We don't know how to go about it because we don't know our leaders.

While members of the school community may have had mixed views on the role of students in the decision-making process, virtually everyone believed parental participation in the process was non-existent. The primary vehicle for parent voice was the Parent Council, even though it was, as Marie, one of the few parents who was involved in the council emphasized, "just an advisory board." She observed that "you really just only relay information and challenges that the community or the students or the parents have as a whole, you bring it to the principal." In the school's third year, 10 parents showed up to the first meeting. However, attendance dwindled to three in subsequent meetings. Brian, a senior student, felt that while parents 
had an opportunity to have a say, they chose not to exercise this option. He said, "It's like they can voice their opinion, but I think they just choose not to because [these] are the expectations."

At Adam Bower, leadership was just one aspect of the inclusive initiatives. Rob and Jean and supportive members of the school community also attempted to make the programs they offered inclusive.

\title{
Designing and Sustaining Inclusive Programs
}

Rob, and then Jean, worked to design and sustain practices that ensured that students (and their parents) were included in school programs. Both took seriously the district equity/inclusion policy and did their best to infuse its spirit into the school. One of the first things Rob did was to put together a school committee to oversee its implementation at Adam Bower. Bill, one of the committee members, maintained that the committee was designed to look critically "at sexism, heterosexism, racism, ageism, able-ism, faith as an 'ism." The committee sought to "make sure all the practices within the school, all interactions with students as well as the parents [were] done in an equitable manner." In the first couple of years, it focused on "making sure that teachers as a whole understood various issues of equity and where they stood." The committee, "with the full support of the administration," conducted a number of in-house sessions that addressed these various issues. The emphasis on equity continued into the third year. Jean was actually a key member of the district committee that designed the equity policy and she continued to champion it within the school. For her, equity and inclusion needed to permeate the entire school:

\begin{abstract}
It's not just the teacher in front of the classroom, it's not just textbook, but it's everything we do in this building, right down to the way people are greeted in the office, to the way they're treated and greeted in the hallways, how students interact with the teachers, how community comes in and how we interact with them, how we interact as a staff, that kind of stuff. And how the kids interact with each other.
\end{abstract}

These principles were reflected in a number of ways within the school. These included the way in which diversity was approached, the specialized programs, pedagogy, and curriculum. The first year of operation, however, brought with it conflict between groups of students. Rob, for example, spoke of the "many levels of tensions." On the first day of school, he took a construction pick from one of the student combatants in a fight. These tensions eased in the second year when one of the groups of students that was temporarily housed at Adam Bower departed for their new school. Through all of this, administration and staff at Adam Bower emphasized the importance of honouring different cultures. They featured various performances, hosted lunches, supported displays, and held "culture days." Flags, artwork, and pictures from different parts of the world commonly adorned the walls of the school and classrooms during this time. The school also sponsored Black History Month and South Asian Month, and continues to do that, although reviews on the practice are mixed. John, a staff member, for example, contended,

I know it's nice to have Black History Month. I know it's great that we have South Asian Heritage Month. But we need to stop doing those things and start realizing that we are in a multicultural community, and start celebrating culture as a whole. So when we have Black History Month, we need to include all cultures in Black History Month in order to be part of the celebration. We had a holiday fest and it became again, the Blacks did their show, Indians had their show, and then the others had their show. That's not inclusive. 
As the third year rolled around, students appeared to come to terms with their diverse school environment. Although it is not known whether the school's diversity-related initiatives had any impact, a number of students maintained that the school had become a more comfortable place for them. Jody, for example, a senior student of African heritage, said that

In Grade 10 (2 years ago), the Indians used to be racist to the Black people. Like they just didn't like us. If you were to touch them by accident, they'd want to fight you. And then I guess as we got older, everyone realized that it's stupid. So everyone became friends. Like it doesn't matter your skin colour or race or whatever. We're just all friends.

The two principals and those with whom they worked sought to design and put into practice special programs that included marginalized students. One of the first things that Rob and the department heads he first hired did was to build a profile of the new students so they could design programs that would include them and allow them to be successful. He said that they "built a profile of every incoming kid-1200 students." In order to do so they looked at report card data, standardized external measures from EQAO, board testing, social work support, among other sources of information. "Out of that profile, we built the program and the interventions that we felt we needed to support our kids and help them be successful."

Rob also tapped into funding sources that provided the school with more resources to ensure that all students had an opportunity for success. Two programs that Rob and later Jean fostered included an afterschool tutoring program and a drop-in initiative. The first program of this sort was the tutoring program where students requiring assistance completing credits could receive help after school 2 days a week. While Rob emphasized the success of the program, pointing out that "no student failed French last year at Adam Bower because of [the after-school program]," others more recently pointed out its exclusive character. John, a staff member, said the program catered almost exclusively to South Asian students. He contended that students of African heritage were not likely to seek help because they were unlikely to enter a room where "There's no one who resembles me." John went on to ask, "What's left for the Black kids? There's not really anything."

The second program was a type of drop-in initiative that attempted to meet challenges beyond academic needs. Geared for students experiencing behavioural and academic problems, it offered a haven for students to get help with their difficulties. According to one staff member, the program really did not "do anything productive" in the first 2 years. He contended, "we had a lot of kids who were just using the room as an excuse not to go to class, or almost like it was a crutch." In the third year, Jake, who worked in the program, said the goal was to "take away the atmosphere of "We're hanging out." He maintained that now all students who come down to the room "were going to do some serious work" and communication with students' teachers increased. This adjustment required a re-education of some students who were not all happy with it. However, Jake contended that this change paid off: More students who accessed the service attained credits and the centre achieved "a lot of admiration not only from all the staff and administration, but the kids as well." Not all were happy with everything that occurred. Justine, a senior student, did not like what she perceived as the subsequent loss of the previous atmosphere:

Whenever like someone was pissed off or whatever, it was just a room where you could go to talk about your problems and like cool down, and at the same time, get some work done. And at the same time, you know, have some fun. But you can't do that anymore. 
Staff at Adam Bower also sought to include all students in the curriculum that they offer and the pedagogy that teachers employed. Both Rob and Jean appeared to have made serious efforts to promote inclusive classroom practices. Despite the hard work and good intentions of Adam Bower's administrators and teachers, there had always been a tenuous relationship between the school's inclusive ideals and what actually happened in the classroom. Some teachers attempted as far as they could to follow through on the inclusive work that the staff had addressed in the PLC. For example, Janice, a teacher, felt that staff members generally made an effort to ensure that students had a voice. Other teachers approached inclusion in other ways. Wayne, for example, taught the "isms" to his "special ed." students through, among other things, film. He said, "We have to teach the 'isms' because our students by definition can be excluded because of their learning disabilities or because of physical disabilities or because of any number of things." His hope was that teaching these topics to his students would help them "understand the nature of discrimination because they may well have to find ways to fight it themselves."

Not all teachers at Adam Bower, however, attempted to adapt the curriculum in inclusive ways or took pains to acknowledge the uniqueness of their students. Brian, a staff member, noticed that "a lot of our Black kids feel like they're left out because they don't have enough representation." He said that they do not really see anything that "represents themselves to make them want to be a part of it." Brian further added that the curriculum "doesn't represent what is in this building." While they compliment some teachers, students also expressed dissatisfaction with other teachers' efforts to include others who have their own ways of learning. Chantal, for example, said,

Some people learn different and so you need to be able to like you know, involve peoples' learning ability into your lessons and stuff. And some teachers don't do that. They think that their way is the way that students are going to learn. Well, students aren't going to learn. Like it just makes them skip and stuff.

Some teachers believed that they were limited in the ways in which they could approach the curriculum, and thus in the kinds of inclusive practices in which they could engage. Brickley maintained that "I have a direction that I have to follow; here's the curriculum that I have to follow, there's no 'ifs,' 'ands,' or 'buts." He contended that "we can deter away from some of those things, but not by much because you still have to follow whatever the Ministry sets down." Others, however, feel a greater sense of freedom. Janice is one of these teachers. She said, "You can make an inclusive environment yourself; so it's totally up to me to make it inclusive."

Administrators at Adam Bower have struggled from the beginning to encourage parents to become involved in the operations of the school. The meagre participation of the parent council reflected the participation of parents in other aspects of the school. Jean said that "one of the most difficult things I'll have as a principal to do is to get people involved here from the community." For the most part, the events that the school organized for parents were poorly attended. While more parents seemed to come out for "parent night," few attended other activities designed, for example, to inform them of academic disciplines like literacy or mathematics or about potential career paths for their children.

Members of the school community cited many reasons for the reluctance of parents to become involved in school activities. They included the fact that the parents of secondary school students are generally less inclined to participate, that parents are reluctant to interact with school officials when previous contact has been mostly negative, that their busy work schedules do not coincide with the timing for parent events, or that they are not confident of their ability to speak 
English. Perhaps the most cited reason for non-involvement is "cultural." Pointing to the South Asian parents, many believed that they would prefer to leave the education of their children in what they feel are the competent hands of educators.

The school has taken measures to overcome this reluctance to become involved in school activities. Among other things, it used the services of a local newspaper, employed translation services, and designed activities that targeted particular cultural groups. Members of the school community, however, had mixed feelings about the school's efforts to involve parents. Noreen, a teacher, said on the one hand that she had "never been in a school where there's been so much done to invite parents in." John, on the other hand, believed that the school was not doing enough. He said, "We're really not reaching out to the parents and we need to reach out to the parents in the community in a way that's going to be more proactive, helping the kids' parents understand... how the school system works." One of the more successful recent events employed additional promotional tactics. Making use of the services of a number of teacher interns, the school first sent out flyers in the language of the group they wished to attract and then followed up with phone calls to the parents. This event, however, was the exception to the rule. Roger, a staff member, emphasized that if the school was to enjoy more success in getting parents to become involved in the school then it needed to be more patient, consult parents about activities, and better understand the community.

\section{Discussion}

The prospects for making Adam Bower an inclusive school seemed promising even before it opened its doors to students. To begin with, the appointed principal, Rob Powers, was committed to the principle of inclusion. He worked behind the scenes for a year, hiring people whom he believed would embrace his inclusive ideals and planning with them the various school programs. By its third year, Adam Bower would display many inclusive practices both within its programs and in its leadership structure. The school benefited from two principals who were open to input from others and encouraged and supported inclusive practices. Both Rob and Jean have facilitated the adoption of inclusive practice in the school in the manner of other inclusive principals (see, for example, Ryan, 2006a). They provided students with the chance to exercise their voice through organizations like the student council and teachers with opportunities to share their expertise and learning with colleagues. They have also provided venues for looking critically at issues like racism and sexism, promoted the practice of honouring different cultures, and worked with others to put in place specialized programs that were geared for all marginalized students. The two principals have also made it possible for teachers to find ways to include all students through their pedagogy and the ways in which they approach the curriculum.

Despite these achievements, the path to this point has not been smooth. Members of the school community have struggled in their efforts to embed inclusion in the culture of the school. While they have made some progress, they have also seen a degree of backsliding. Along the way they have had to cope with the appointment of a new principal, a rapid increase in the school population, as well as the trials and tribulations that accompany most schools when they attempt to implement inclusive practices.

The first significant hurdle that Adam Bower had to scale was the departure of Rob Powers. Rob had been the driving force behind the school's inclusive spirit, and so his exodus was bound to have an impact on the whole school community. But not all changes associated with the principal succession were negative. First, and most important, the district saw fit to appoint an- 
other inclusive-minded principal to the position. Jean was a well-known advocate of inclusion and when she arrived she did her best to extend Rob's inclusive initiatives. In situations like these, where succeeding principals have similar priorities, succession tends to generate less disruption to schools (Corbett, Dawson, \& Firestone, 1984). Schools also tend to be more successful when the new principal "fits" the school (Davidson \& Taylor, 1998). In some respects, Jean was a good fit, given her willingness to invest in the existing inclusive programs and in the decisionmaking structures. In other respects, though, Jean was a less-than-ideal fit. Among other things, she had to follow a charismatic individual who laid the foundation for what she inherited at the school.

Fullan (1992) contends that the departure of charismatic principals who radically transform schools in 4 or 5 years can disrupt change processes. While Rob may or may not have been characterized as charismatic, many teachers were devoted to him. He did, after all, hire most of them, and many, like Wilbur, looked to Rob to provide direction for the school. So his departure left a hole. And while Jean embraced Rob and Adam Bower's vision, she did not always pursue it in the manner in which Rob did. Among other things, she did not take up Rob's hands-on style of leadership. When he was principal, Rob made a practice of dropping in on the learning community sessions, often taking part. Jean and her vice principals did not do this, preferring to leave things to the teachers. Not all teachers appreciated this. Some, like Wilbur, felt that it demonstrated a lack of support for their efforts at a time when they could have used some reassurance.

The principal turnover was not the only issue that impeded the drive for inclusion. Other environmental factors, such as the changing and expanding student population, also slowed the school's attempts to attain this goal. In the beginning, Rob's dream was to nurture a community school-one that was small enough to integrate the community into its operations. But even before the school opened to students, Adam Bower was forced to provide a temporary home for students who could not be accommodated in other facilities. The conflict that ensued among the various groups of students was short-lived, however, and it dissipated when these students moved on. Even so, the rapid growth of the student population over the 3 years of its existence continued to make it more difficult to instil an inclusive culture. As time passed it became more difficult to reach students and parents, and some of the newer teachers turned out not to be as committed to inclusion as the ones who were initially hired by Rob. This led to what Rob referred to as "drift" from the initial school philosophy. The drift showed up from time to time in the attitudes of teachers to inclusion, perhaps most eloquently demonstrated in the opposition to giving students a say in the school schedule.

Adam Bower also encountered obstacles to inclusion that other school communities experience. School staff had difficulty encouraging the community to become involved in school activities, encouraging teachers to understand diversity-related issues, and translating inclusive ideals into classroom practices. Adam Bower is not alone in this regard. For example, many other diverse schools are not able to involve parents in their various activities (Ryan, 2003). The reasons supplied for these challenges mirror those identified by Adam Bower staff and parentsprevious negative experiences with schools, busy work schedules, lack of confidence, and a belief that education should be left in the hands of the experts (Ryan, 2002). Despite persistent efforts over the years to include parents, relatively few parents have seen fit to involve themselves in Adam Bower activities.

From the outset, Adam Bower experienced difficulties in getting staff to understand diversity-related issues and translate their inclusive philosophy into classroom practice. One of the challenges revolved around the belief that activities — whether they be weekly or monthly—that 
were devoted to particular cultural groups were inherently inclusive. A few staff members recognized the shortcomings of these initiatives, but most did not. Another difficulty revolved around the translation of inclusive philosophies to the classroom. While a few teachers were able to do this, many others were not. Both students and staff note that groups of students, such as the African Canadians, had difficulty seeing themselves in the curriculum and being able to learn within the existing teaching styles. Some teachers, on the other hand, claim that it was difficult to target inclusive issues because they were limited by existing curriculum guidelines.

\section{Conclusion}

It is difficult to introduce inclusion at the best of times. Most schools struggle when they attempt to do this. Often this is because an already entrenched culture resists efforts to change it. But what happens if there is no already-established culture, as in the case of new schools that are geared to promote inclusive practice? This study was designed to explore this issue. It examined the first 3 years of a new school that attempted to introduce and entrench inclusive practice. The first principal of the school was a strong proponent of inclusion, and in the year before the school actually opened, hired those he believed would support this inclusive vision. When the school opened he initiated various committees, councils, and programs that he believed would make it possible for students, parents, and teachers to become meaningfully involved in the operation and activities of the school. Not all went as planned, however. The first significant obstacle to inclusion occurred when this principal left the position after the school's second year of operation. While the new principal was also committed to inclusion, she encountered resistance from some staff members who had been committed to her predecessor and who objected to her different leadership style. The rapidly expanding school also complicated inclusive efforts. Some of the newer teachers did not embrace inclusion in the same way as those initially hired by the first principal. Other issues also obstructed inclusion: programs designed to assist students favoured particular groups; teachers had difficulty translating inclusive ideas into their teaching and curriculum offering; cultural programs only superficially touched on inclusive issues; and parents resisted efforts to get them involved in school activities.

While this is only one case study, it offers a few lessons. The first is that entrenching particular values like inclusion in a new school will probably not be a straightforward enterprise. It will inevitably be complicated by any number of influences and complications, many coming from outside sources that cannot be controlled. In these circumstances, educators need to be flexible and deal with these complications when they arise. Perhaps the most important lesson that those who look to promote inclusion can learn from this and other cases is that inclusion is an ongoing process. Ainscow (2005) contends that it is unlikely that complete inclusion will ever be achieved. This means that those who advocate for it will find themselves constantly struggling against obstacles in highly contested environments to promote their inclusive goals. They should not be discouraged when they have difficulty attaining complete inclusion, however, and they should be prepared to struggle in order to protect their gains.

Future research can also generate knowledge about implementing and sustaining inclusive practice in schools. It would be helpful to study other new schools to see how they manage the obstacles to inclusion. It would also be interesting to see how a school that retains its original principal succeeds with it inclusive priorities, how administrators deal with resistance to their inclusive philosophies, and how they go about establishing inclusive cultures. We can also learn about inclusive practice from case studies of longstanding schools. No two case studies will be 
alike, and much can be learned from different contexts. Finally, surveys of inclusive practice can generate useful knowledge of how best to introduce and sustain inclusive practice in new and old schools.

\section{References}

Ainscow, M. (2005). Developing inclusive education systems: What are the levers for change? Journal of Educational Change, 6, 109-124.

Ancess, J. (1997). Urban dreamcatchers: Launching and leading new small schools. Retrieved October 22, 2009, from http://www.smallschoolsproject.org/index.asp?siteloc=start\&section=newsmall

Blase, J., \& Blase, J. (1997). The fire is back? Principals sharing school governance. Thousand Oaks, CA: Corwin.

Blase, J., \& Blase, J. (1999). Principals' instructional leadership and teacher development: Teacher' perspectives. Educational Administration Quarterly, 35(3), 349-378.

Blase, J., \& Dungan, S. (1994). Tabula rasa: Case studies of shared governance. School Organization, 14(2), 207-218.

Bolin, F. (1989). Empowering leadership. Teachers College Record, 91(1) 81-96.

Booth, T. (1996). A perspective on inclusion from England. Cambridge Journal of Education, 26(1), 8799.

Bredeson, P. (1989). Redefining leadership and the roles of school principals: Responses to changes in the professional worklife of teachers. The High School Journal, 73, 9-20.

Byrne, D. (1999). Social exclusion. Philadelphia: Open University Press.

Conley, S. (1991). Review of research on teacher participation in school decision making. In G. Grant (Ed.), Review of research in education (pp. 225-265). Washington, DC: American Educational Research Association.

Coombs, C. (2002). Reflective practice: Developing habits of mind. Unpublished doctoral dissertation, University of Toronto, ON.

Corbett, H. D., Dawson, J., \& Firestone, W. (1984). School context and school change: Implications for effective planning. Philadelphia: Research for Better Schools.

Corson, D. (1996). Critical policy making: Emancipatory school-site leadership in multi-ethnic schools. Forum of Education, 52(2) 132-156.

Datnow, A., \& Castellano, M. (2001). Managing and guiding school reform: Leadership in Success for All Schools. Educational Administration Quarterly, 37(4), 219-249.

Davidson, B. M., \& Taylor, D. L. (1998, April). The effects of principal succession in an accelerated school. Paper presented at the Annual Meeting of the American Educational Research Association, San Diego, CA.

Dei, G., James, I. M., Karumancherry, L. L., James-Wilson, S., \& Zine, J. (2000). Removing the margins: The challenges and possibilities of inclusive schooling. Toronto, ON: Canadian Scholar's Press.

Duke, D., Showers, B., \& Imber, M. (1980). Teachers and shared decision making: The costs and benefits of involvement. Educational Administration Quarterly, 16(1) 93-106.

Epp, J., \& MacNeil, C. (1997). Perceptions of shared governance in an elementary school. Canadian Journal of Education, 22(3) 254-267.

Fullan, M. G. (1992). Visions that blind. Educational Leadership, 49(5), 19-20.

Fullan, M. (2001). The new meaning of educational change (3rd ed.). New York: Teachers College Press.

Gillborn, D. (1995). Racism and antiracism in real schools. Philadelphia: The Open University Press.

Glickman, C., Allen, L., \& Lunsford, B. (1994). Voices of principals from democratically transformed schools. In J. Murphy \& K. S. Louis (Eds.), Reshaping the principalship: Insights from transformational reform efforts (pp. 203-218). Thousand Oaks, CA: Corwin.

Jennings, W. (1992). Starting new schools: Lessons for success. (ERIC Document Reproduction Service No. ED346591). 
Keys, M., Hanley-Maxwell, C., \& Capper, C. (1999). Spirituality? It is the core of my leadership: Empowering leadership in an inclusive elementary school. Educational Administration Quarterly, $35(2), 203-237$.

Kirby, P. (1992). Shared decision making: Moving from concerns about restrooms to concerns about classrooms. Journal of School Leadership, 2(3), 330-345.

Lake, R., Winger, A., \& Petty, J. (2002). The new schools handbook. Seattle, WA: Center on Reinventing Public Education.

Leithwood, K., Jantzi, D., \& Steinbach, R. (1999). Changing leadership for changing times. Buckingham: Open University Press.

Lupart, J. (1998). Setting right the delusion of inclusion: Implications for Canadian schools. Canadian Journal of Education, 23(3), 261-264.

Madanipour, G., Cars, G., \& Allen, J. (Eds.). (1998). Social exclusion in European cities. London: Jessica Kingsley.

Merriam, S. D. (1998). Qualitative research and case study applications in education. San Francisco: Jossey-Bass.

Munck, R. (2005). Globalization and social exclusion: A transformationalist perspective. Bloomfield, CT: Kumarian.

North American Montessori Teachers Association. (2009). Starting a new Montessori school. Retrieved October 22, 2009, from http://www.montessori-namta.org/namta/administrators/startsch1.html

Oakes, J., \& Lipton, M. (2002). Struggling for educational equity in diverse communities: School reform as social movement. Journal of Educational Change, 3(4), 383-406.

Ontario Ministry of Education. (2009). Realizing the promise of diversity: Ontario's equity and inclusive education strategy. Toronto, ON: Ontario Ministry of Education.

Riley, E. K., \& Rustique-Forrester, E. (2002). Working with disaffected students. London: Paul Chapman.

Rizvi, F. (1993). Race, gender and the cultural assumptions of schooling. In C. Marshall (Ed.), The new politics of race and gender (pp. 203-217). Bristol, PA: Falmer Press.

Ryan, J. (2002). Promoting inclusive school-community relationships: Administrator strategies for empowering and enabling parents in diverse contexts. Journal of Teaching and Learning, 2(1), 1-20.

Ryan, J. (2003). Leading diverse schools. Dordrecht: Kluwer.

Ryan, J. (2006a). Inclusive leadership. San Francisco: Jossey-Bass.

Ryan, J. (2006b). Inclusive leadership and social justice for schools. Leadership and Policy in Schools, $5(1), 3-17$.

Ryan, J. (2007). Dialogue, indentity and inclusion: Administrators as mediators in diverse school contexts. Journal of School Leadership, 17(3), 340-369.

Ryan, J., \& Rottmann, C. (2009). Struggling for democracy: Administrative communication in a diverse school context. Education Management, Administration and Leadership, 37(4), 473-496.

Short, P., \& Greer, J. (1997). Leadership in empowered schools: Themes from innovative efforts. Columbus, OH: Prentice-Hall.

Slee, R. (2001). Social justice and the changing directions in educational research: The case of inclusive education. International Journal of Inclusive Education, 5(2/3), 167-177.

Smylie, M., \& Brownlea-Conyers, J. (1992). Teacher leaders and their principals: Exploring the development of new working relationships. Educational Administration Quarterly, 28(2) 150-184.

Statistics Canada. (2009). Census tract profile for 0576.10 (CT). Retrieved October 5, 2009, from http://www12.statcan.ca/census-recensement/2006/dp-pd/prof/92597/P3.cfm?Lang=E\&CTCODE=5761\&CACODE=535\&PRCODE=35\&PC=L6R2Z4

Theoharis, G. (2007). Social justice education leadership and resistance: Toward a theory of social justice leadership. Educational Administration Quarterly, 43(2), 221-258.

Thousand, J., \& Villa, R. (1994). Managing complex change towards inclusive schooling. In R. Villa \& J. Thousand (Eds.), Creating an inclusive school (pp. 51-79). Alexandria, VA: Association for Supervision and Curriculum Development. 
UNESCO. (2003). Overcoming exclusion through inclusive approaches in education: A challenge and a vision. Paris: UNESCO.

Walker, A., \& Walker, C. (Eds.). (1997). Britain divided: The growth of social exclusion in the 1980s and 1990s. London: Child Poverty Action Group.

Walker, A., \& Walker, J. (1998). Challenging the boundaries of sameness: Leadership through valuing difference. Journal of Educational Administration, 36(1) 8-28.

Wallace, M. (2001). Sharing leadership of schools through teamwork: A justifiable risk? Educational Management \& Administration, 29(2) 153-168.

\section{Author's Note}

Correspondence concerning this article should be addressed to Jim Ryan, Department of Theory and Policy Studies, The Ontario Institute for Studies in Education, 252 Bloor St. West, Toronto, ON, M5S 1V6. Email: jim.ryan@utoronto.ca 